\title{
Harvest-aid application strategy in different cotton planting densities by unmanned aerial vehicle
}

\author{
Yanhua Meng ${ }^{1,2,3}$, Yuxing Han ${ }^{1,2}$, Zjing Liang ${ }^{3}$, J inya Sü*, Yubin Lan ${ }^{1,2^{*}}$ \\ (1. National Center for International Collaboration Research on Precision Agricultural Aviation Pesticide Spraying Technology, \\ South China Agricultural University, Guangzhou, 510642, China; \\ 2. College of Electrical Engineering, South China Agricultural University, Guangzhou, 510642, China; \\ 3. Key Laboratory of Aviation Plant Protection, Ministry of Agriculture and Rural Affairs, Anyang, 455000, China; \\ 4. School of Computer Science and Electronic Engineering, University of Essex, Colchester, CO4 3SQ, U.K.)
}

\begin{abstract}
Harvest aids are widely used for defoliating leaves and accelerating the opening of green bolls to facilitate machine harvesting in cotton (Gossypium hirsutum L.) production areas. Cotton harvest aids applied by ground-based mechanical sprayers are inefficient due to mechanical damage to cotton crops and soil and low flexibility. For the last few years, small plant protection unmanned aerial vehicles (UAVs) have been used for applying pesticides across the world due to their high efficiency, high pesticide utilization, low volume and no harmful damage to crops and soil. This study mainly focuses on developing the technology of harvest aid application by UAVs with respect to the dosage and application frequency. Compared with previous studies, this work performs miscellaneous field trials for two years in three experimental sites located in high-density planting areas and two sites in sparse-density planting areas, wherein both cotton cultivation modes and weather conditions are different. In the study, single-round, dual-round and reduced dosage applications are tested, where the defoliation rate, boll opening rate, fiber quality and lint cotton yield are assessed based on the collected data. It is concluded from the experimental results that the achieved defoliation rate and boll opening rate of treatments with a single-round application using the recommended dosage fail to meet the harvest requirements in the case of high planting density (180,000-195,000 plants/ $\mathrm{hm}^{2}$ ). However, with the dual-round application of the exact recommended dosage or $20 \%$ lower than the recommended dosage, the achieved defoliation rate, and boll opening rate meet the machine harvest requirements. In sparse-density planting areas $(\leq 90,000$ plants/ha), the results of treatment with the recommended dosage and single-round application by UAV spraying meet the requirements. In all the experimental sites, the harvest-aid dosage and application frequency do not affect fiber quality and lint cotton yield. In summary, considering the cost and environmental protection, harvest aid application by UAVs with a dual-round application at $80 \%$ of the recommended dosage at a 7 -day interval is encouraged in high-density planting areas, while in sparse-density planting areas, single-round application of harvest aids at the recommended dosage by UAVs is encouraged. The results provide paramount guidance for cotton farmers and scholars in this field. Possible future studies are also discussed in this paper.
\end{abstract}

Keywords: cotton, unmanned aerial vehicle, harvest aid application strategy, dosage, application frequency DOI: $10.33440 /$ j.ijpaa.20190201.0027

Citation: Meng Y H, Han Y X, Liang Z J, Su J Y, Lan Y B. Harvest-aid application strategy in different cotton planting densities by unmanned aerial vehicle. Int J Precis Agric Aviat, 2019; 2(1): 30-40.

\section{Introduction}

Cotton, as the most abundant natural fiber, is produced and consumed in many countries ${ }^{[1]}$. Mechanization that can greatly reduce labor input plays an important role in cotton production from sowing to harvesting ${ }^{[2]}$. A fully mechanized cotton production technology system is successfully constructed in a high-density cultivation mode area ${ }^{[2,3]}$, which includes a drip irrigation system covered by mulch, precision seeding, wide-film mulching, integration of water and fertilizer, field management for

\section{Received date: 2019-09-17 Accepted: 2019-09-20}

Biographies: Yanhua Meng, $\mathrm{PhD}$ candidate, research interests: agricultural aviation application and pests \& diseases management, Email: yanhua.meng@ outlook.com; Yuxing Han, $\mathrm{PhD}$, Professor, research interests: internet technology applied in precision agricultural, National Center for International Collaboration Research on Precision Agricultural Aviation Pesticide Spraying Technology, South China Agricultural University, Guangzhou 510642, China. Tel: 020-85288202, Email: yuxinghan@scau.edu.cn; Zijing Liang, Engineer, research interests: agricultural aviation application. Email: 925913277@qq.com. pesticides applied by ground-based sprayers or other novel sprayers and mechanized harvest. In this fully mechanized cotton production technology system, some aspects still need improvement. For instance, harvest aids are applied on the cotton canopy by ground-based mechanical sprayers to defoliate leaves and ripen bolls to facilitate the mechanized harvest. Tractors equipped with large tanks, long booms and dozens of nozzles are usually adopted as harvest-aid application sprayers. During the application, these tractors usually flatten the cotton bolls when turning and knocking down the opened bolls due to its heavy

\footnotetext{
* Corresponding author: Yubin Lan, PhD, Professor, research interests: agricultural aviation application. National Center for International Collaboration Research on Precision Agricultural Aviation Pesticide Spraying Technology, South China Agricultural University, Guangzhou 510642, China. Tel: +86-20-85281421, Email: ylan@scau.edu.cn;.

Jinya Su, PhD, Lecturer, research interest: autonomous systems and their applications in smart farming. School of Computer Science and Electronic Engineering, University of Essex, Colchester, CO4 3SQ, U.K. Tel: +44-(0)1206872431, Email: j.su@essex.ac.uk.
} 
wheels; this not only results in yield loss by increasing waste content but also leads to soil compaction ${ }^{[4,5]}$. Additionally, the overuse pesticides in agriculture leads to pesticide poisoning, environmental pollution and diminishing biodiversity; this phenomenon could be caused by many factors. For example, farmers increase the pesticide application frequency and dosage to control pest outbreak due to pest resistance to a single kind of pesticide and their barriers to technology ${ }^{[6]}$. In applying pesticides or cotton harvest aids, there is an urgent need of advanced spraying technology that reduces crop/soil damage and improves pesticide utilization efficiency. It is reported that fixed-wing aircraft is used for harvest aids application for low-volume spraying (60$\left.90 \mathrm{~L} / \mathrm{hm}^{2}\right)$ due to its high working efficiency (8.38 times greater than the ground-based mechanical sprayers) and a lack of mechanical damage to the cotton plant and soil ${ }^{[7]}$. When a single-round application strategy is adopted, the results show that the performance of aerial spraying is inferior to the ground-based mechanical sprayers because of the poor penetration of droplets in the high-density planting area.

In recent years, UAVs have been widely used for spraying pesticides to control pests and diseases. The advantages of aerial application of pesticides by UAVs is substantial, such as high working efficiency, no harmful mechanical damage to crops and soil, low water consumption, reduced pesticide poisoning, high pesticide utilization and high flexibility ${ }^{[8-17]}$. Global positioning system (GPS), geographic information system (GIS), BeiDou navigation satellite system (BDS) and real-time kinematic (RTK) automatic navigation technology have been used in the flight control system for precision spraying by UAVs. As an intellectualized equipment, UAVs have played an important part in the development of precision agriculture. Compared with traditional ground-based mechanical sprayers that have a high-volume spraying mechanism, the UAV-based sprayers display the following advantageous characteristics: a downwind produced by rotors, nozzles 1-2 meters above the upper canopy, low-volume high-concentration spraying and auto-navigation intelligence and smart spraying. Relevant work has been performed on the droplet distribution in the crop canopy, biological control efficacy, droplet drift, and pesticide residue ${ }^{[10,13,18-21]}$. With respect to cotton crops, UAVs have also been used for applying harvest aids. In the high-density cotton production area, in one field site, the defoliation rate and boll opening rate are evaluated by four types of UAVs according to a dual-round application with a 7-day interval; for each UAV, spraying volumes of $12 \mathrm{hm}^{2} / \mathrm{L}, 18 \mathrm{hm}^{2} / \mathrm{L}$ and $22.5 \mathrm{hm}^{2} / \mathrm{L}$ are used, and the harvest aid recommended dosage is applied; the results show that the defoliation rate of treatment with $22.5 \mathrm{hm}^{2} / \mathrm{L}(97.6-100 \%)$ is best $21 \mathrm{DAT}$, and the UAV spraying does not affect the cotton yield or the fiber quality component ${ }^{[22]}$. It is reported that with single-round spraying by a multiple-rotor $\mathrm{UAV}$, the achieved defoliation rate $(91.5 \%)$ is lower than required (95\%), and the achieved boll opening rate $(89.4 \%)$ is lower than required $(90 \%)$ as well ${ }^{[21]}$. It is observed that defoliant dosage has no significant impact on fiber quality and cotton yield in a dual-round spraying strategy by a UAV in the sparse-density planting area ${ }^{[23]}$. In high-density planting area, it is reported that the required defoliation rate is achieved when the spraying volume $\geq 18 \mathrm{~L} / \mathrm{hm}^{2}$ with flight velocity no more than $5 \mathrm{~m} / \mathrm{s}^{[14]}$.

Although there are some field studies about harvest aid application by UAVs on cotton, research on harvest aid dosage combined with the application frequency (single- or dual-round) by
UAVs is rarely reported. Second, these reports do not study the feasibility of dosage reduction for dual-round application technology, which could be meaningful for eliminating both pesticide residue and costs. Third, previous studies have utilized single- or dual-round applications in one site, or a dual-round application in two sites in one or two years. More tests in even more sites with similar or different weather conditions and/or similar or different cotton densities could be helpful in drawing more convincing conclusions. In this article, the combination of dosage and application frequency on defoliation efficacy, boll opening rate, lint cotton yield and fiber quality are studied according to a UAV-based, low-volume spraying method in five experimental sites for comparison (three sites in the Northwest inland cotton region (Xinjiang) and two sites in the Yellow River valley cotton region (Henan)); these sites have different cotton densities and under different weather conditions in China in 2017 and 2018, respectively. Before conducting normal tests for harvest aids application, two different spraying volumes are tested by evaluating the droplet coverage with water-sensitive paper (WSP) in the cotton canopy in 2017 in order to identify an optimal volume. The spraying volumes $\left(18 \mathrm{~L} / \mathrm{ha}\right.$ and $22.5 \mathrm{~L} / \mathrm{hm}^{2}$ ) yielding larger droplet coverage are adopted for harvest aids application. The arrangement of treatments in the three experimental sites in Xinjiang is the same (three UAV treatments and one tractor treatment) as that in the other two sites in Henan (two UAV treatments and one knapsack treatment); the same chemical harvest aids and UAVs are used in all sites. The purpose of this study is to develop a harvest-aid spraying strategy for cotton in different cultivation modes by UAV-based low-volume spraying in different cotton planting regions. Based on the plethora of data collected during the tests, the feasibility, merits and optimal parameters of UAV spraying are analyzed. The results indicate that with a spraying volume of $22.5 \mathrm{~L} / \mathrm{hm}^{2}$, it is feasible to use UAVs to apply a dual-round of $80 \%$ of the recommended harvest-aid dosage in high-density planting areas; in sparse-density planting areas, it is feasible to apply a single-round UAV spraying of the recommended harvest-aid dosage.

The remainder of the paper is organized as follows. Section 2 introduces the materials and methods for conducting the test. Section 3 provides the results of field trials. Section 4 analyses dosage of the harvest aid and the application frequency on the defoliation efficacy, boll opening rate, fiber quality and lint cotton yield based on the collected results and presents future work. Section 5 summarizes the observations and analysis of this paper.

\section{Materials and methods}

\subsection{Experimental sites}

Field experiments are conducted in the following five experimental sites in the 2017 and 2018 cropping seasons in China: Site I - Ershilidian Town $\left(44^{\circ} 17^{\prime} \mathrm{N}, 8^{\circ} 97^{\prime} \mathrm{E}\right)$ in Hutubi County, Xinjiang Uygur Autonomous Region where cotton is planted with alternating row spacings of 10 and $66 \mathrm{~cm}$; Site II - Yellow River valley cotton production area $\left(36^{\circ} 08^{\prime} \mathrm{N}, 114^{\circ} 46^{\prime} \mathrm{E}\right)$ in Anyang city, Henan Province, where cotton is planted with equidistant row spacing of $76 \mathrm{~cm}$; Site III - Farm 150 of Xinjiang Production and Construction Crops $\left(44^{\circ} 57^{\prime} \mathrm{N}, 86^{\circ} 03^{\prime} \mathrm{E}\right)$ in Manasi county, Shihezi City, Xinjiang Uygur Autonomous Region wherein the same cultivation mode is adopted as in Site I; Site IV - Beiquan Town of Xinjiang Production and Construction Crops $\left(44^{\circ} 38^{\prime} \mathrm{N}, 85^{\circ} 98^{\prime} \mathrm{E}\right)$ in Shihezi city, Xinjiang Uygur Autonomous Region wherein the 
same cultivation mode is also adopted as in Sites I and III; Site V Yellow River valley cotton production area $\left(36^{\circ} 04^{\prime} \mathrm{N}, 114^{\circ} 29^{\prime} \mathrm{E}\right)$ in Anyang City, Henan province wherein the same cultivation mode is adopted as in Site II. Cotton has been planted in the experimental fields for many years. The cotton cultivar Xinluzao 64 with a plant height of $73 \mathrm{~cm}$ is planted on 27 April 2017 in Site I and on 29 April 2018 in Sites III and IV, while the cultivar Zhong 79 with a plant height of $115 \mathrm{~cm}$ is planted on 25 April 2017 in Site II and 21 April 2018 in Site V. The plant densities and average number of leaves in the experimental sites are 180,000 plants/ha (Sites I and III, LAI=2.12), 195,000 plants/ha (Site IV, LAI=2.31) and 90,000 plants/ha (Site II and Site V, LAI=1.98), respectively. The 2017 field experiments are conducted in Sites I and II, while the 2018 field experiments are conducted in Sites III, IV and V; mechanical harvesting is adopted in all sites.

\subsection{Sprayers}

An electricity-powered UAV (3WQFTX-10, Quanfeng, China) with GPS autonomous navigation technology is used in the five experimental sites (Figure 1). The UAV is equipped with four rotors, a $10 \mathrm{~L}$ pesticide tank and four flat fan nozzles (Lu120-015, Lechler, Germany). The nozzles are installed under the middle of the rotors in a vertically downward flight direction. The UAV is controlled to $2 \mathrm{~m}$ above the cotton canopy, which results in a $3.5 \mathrm{~m}$ swath during a single spraying. The flight velocity of the spraying is $3-5 \mathrm{~m} / \mathrm{s}$, which is related to the spraying volume and the nozzle flow rate. For research in Site I, Site III and Site IV, a tractor-based (M904-D, Leiwo, China) sprayer is used as a reference; this tractor is equipped with a gas-powered engine, an $11.5 \mathrm{~m}$ boom and a $450 \mathrm{~L}$ pesticide tank. For research in Site II and V, an electrical knapsack (3WBS-D-16B, Xinxiu, China) equipped with a $16 \mathrm{~L}$ pesticide tank and a $60 \mathrm{~cm}$ spray lance is used as a reference.

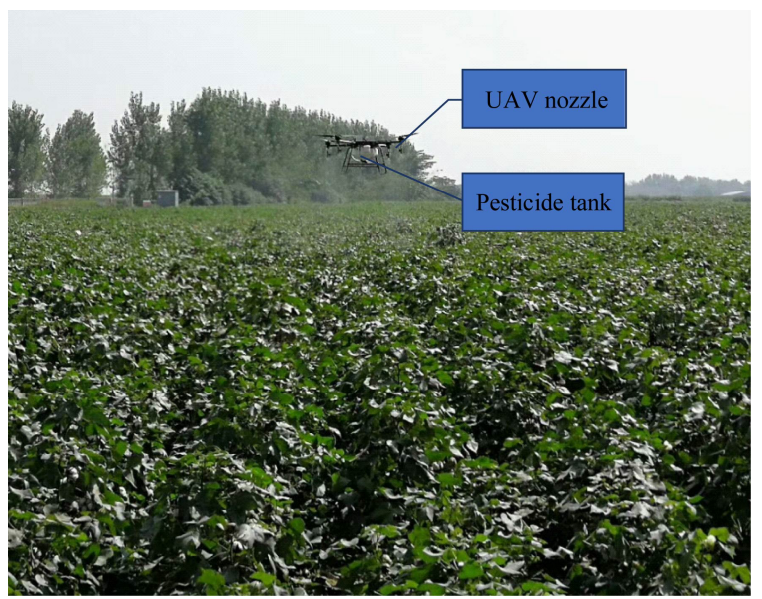

Figure 1 UAV (3WQFTX-10) used in the five experimental sites

\subsection{Harvest aids}

The defoliant, boll opener and spraying adjuvant are usually mixed to get satisfactory defoliation efficacy and boll opening rate. In this study, the defoliant $540 \mathrm{~g} / \mathrm{L}$ thidiazuron diuron SC (Jiangsu Huifeng Biological Co.,Ltd, China), boll opener $400 \mathrm{~g} / \mathrm{L}$ Ethephon AS (Anyang Quanfeng Biological Co.,Ltd, China) and spraying adjuvant $280 \mathrm{~g} / \mathrm{L}$ alkyl-ethyl-sulfonate (Bayer Crop Science China Ltd) are mixed together for foliar spraying in all experimental sites. The dosage and the application frequency in different treatments of the five experimental sites are presented in Table 1.

Table 1 Harvest-aid dosage and application frequency in five experimental sites

\begin{tabular}{|c|c|c|c|c|}
\hline Treatments & Sprayer & Harvest aids & Dosage $/ \mathrm{mL} \cdot \mathrm{hm}^{-2}$ & Application frequency \\
\hline \multicolumn{5}{|c|}{ Site I, Site III and Site IV } \\
\hline I -T1 & \multirow{3}{*}{ UAV } & $540 \mathrm{~g} / \mathrm{L}$ thidiazuron diuron $\mathrm{SC}$ & 180 & \multirow{3}{*}{ Single-round } \\
\hline III-T1 & & $400 \mathrm{~g} / \mathrm{L}$ Ethephon AS & 1050 & \\
\hline IV-T1 & & $280 \cdot \mathrm{g} / \mathrm{L}$ alkyl-ethyl-sulfonate adjuvant & 900 & \\
\hline I -T2 & \multirow{3}{*}{ UAV } & $540 \mathrm{~g} / \mathrm{L}$ thidiazuron diuron $\mathrm{SC}$ & 144 & \multirow{3}{*}{ Dual-round } \\
\hline III-T2 & & $400 \mathrm{~g} / \mathrm{L}$ Ethephon AS & 840 & \\
\hline IV -T2 & & $280 \mathrm{~g} / \mathrm{L}$ alkyl-ethyl-sulfonate adjuvant & 720 & \\
\hline I -T3 & \multirow{3}{*}{ UAV } & $540 \mathrm{~g} / \mathrm{L}$ thidiazuron $\cdot$ diuron $\mathrm{SC}$ & 180 & \multirow{3}{*}{ Dual-round } \\
\hline III-T3 & & $400 \mathrm{~g} / \mathrm{L}$ Ethephon AS & 1050 & \\
\hline IV-T3 & & $280 \cdot \mathrm{g} / \mathrm{L}$ alkyl-ethyl-sulfonate adjuvant & 900 & \\
\hline I -T4 & \multirow{3}{*}{ Tractor } & $540 \mathrm{~g} / \mathrm{L}$ thidiazuron diuron $\mathrm{SC}$ & 180 & \multirow{3}{*}{ Single-round } \\
\hline III-T4 & & $400 \mathrm{~g} / \mathrm{L}$ Ethephon AS & 1050 & \\
\hline IV-T4 & & $280 \cdot \mathrm{g} / \mathrm{L}$ alkyl-ethyl-sulfonate adjuvant & 900 & \\
\hline \multicolumn{5}{|c|}{ Site II and Site V } \\
\hline & \multirow{3}{*}{ UAV } & $540 \mathrm{~g} / \mathrm{L}$ thidiazuron $\cdot$ diuron $\mathrm{SC}$ & 180 & \multirow{3}{*}{ Single-round } \\
\hline II -T1 & & $400 \mathrm{~g} / \mathrm{L}$ Ethephon AS & 1050 & \\
\hline & & $280 \mathrm{~g} / \mathrm{L}$ alkyl-ethyl-sulfonate adjuvant & 900 & \\
\hline \multirow{3}{*}{$\begin{array}{l}\text { II -T2 } \\
\text { V-T2 }\end{array}$} & \multirow{3}{*}{ UAV } & $540 \mathrm{~g} / \mathrm{L}$ thidiazuron $\cdot$ diuron $\mathrm{SC}$ & 144 & \multirow{3}{*}{ Single-round } \\
\hline & & $400 \mathrm{~g} / \mathrm{L}$ Ethephon AS & 840 & \\
\hline & & $280 \mathrm{~g} / \mathrm{L}$ alkyl-ethyl-sulfonate adjuvant & 720 & \\
\hline \multirow{3}{*}{$\begin{array}{l}\text { II -T3 } \\
\text { V-T3 }\end{array}$} & \multirow{3}{*}{ knapsack } & $540 \mathrm{~g} / \mathrm{L}$ thidiazuron $\cdot$ diuron $\mathrm{SC}$ & 180 & \multirow{3}{*}{ Single-round } \\
\hline & & $400 \mathrm{~g} / \mathrm{L}$ Ethephon AS & 1050 & \\
\hline & & $280 \mathrm{~g} / \mathrm{L}$ alkyl-ethyl-sulfonate adjuvant & 900 & \\
\hline
\end{tabular}

\subsection{Weather condition monitoring}

A micro weather station - the Kestrel 5500 Link (Kestrel company, USA) is used to measure air temperature, humidity and wind speed on the treatment day. The weather station is placed
$20 \mathrm{~m}$ away from the treatment area and $1.5 \mathrm{~m}$ above the cotton canopy. To avoid aerial spray drift, the droplet distribution measurements and harvest-aid application are conducted when the wind speed is lower than $3 \mathrm{~m} / \mathrm{s}$. The collected weather data are 
presented in Table 2 .

Table 2 The environmental condition during the droplet coverage measurement and harvest aids application.

\begin{tabular}{|c|c|c|c|}
\hline Time & $\begin{array}{l}\text { Air temperature } \\
{ }_{/{ }^{\circ} \mathrm{C}}\end{array}$ & $\underset{/ \%}{\text { Air humidity }}$ & $\begin{array}{l}\text { Wind speed } \\
\qquad / \mathrm{m}^{-1} \mathrm{~s}^{-1}\end{array}$ \\
\hline \multicolumn{4}{|c|}{ Site I } \\
\hline Droplet measurement & $31.59 \pm 0.89$ & $41.25 \pm 3.15$ & $1.81 \pm 0.52$ \\
\hline Harvest aids application-FR & $29.56 \pm 2.34$ & $40.98 \pm 2.45$ & $1.55 \pm 1.02$ \\
\hline Harvest aids application-SR & $27.43 \pm 1.94$ & $42.88 \pm 2.43$ & $1.65 \pm 0.77$ \\
\hline \multicolumn{4}{|c|}{ Site II } \\
\hline Droplet measurement & $32.43 \pm 1.98$ & $36.77 \pm 3.23$ & $1.13 \pm 0.67$ \\
\hline Harvest aids application-FR & $31.99 \pm 2.33$ & $38.46 \pm 2.23$ & $1.44 \pm 0.92$ \\
\hline \multicolumn{4}{|c|}{ Site III } \\
\hline Droplet measurement & $27.22 \pm 0.51$ & $37.76 \pm 2.15$ & $1.11 \pm 0.72$ \\
\hline Harvest aids application-FR & $27.53 \pm 1.40$ & $39.35 \pm 1.77$ & $1.36 \pm 0.75$ \\
\hline Harvest aids application-SR & $28.77 \pm 2.15$ & $36.56 \pm 2.33$ & $0.87 \pm 0.63$ \\
\hline \multicolumn{4}{|c|}{ Site IV } \\
\hline Droplet measurement & $25.57 \pm 2.12$ & $48.34 \pm 3.47$ & $1.37 \pm 0.85$ \\
\hline Harvest aids application-FR & $26.54 \pm 1.81$ & $45.34 \pm 2.68$ & $1.54 \pm 0.31$ \\
\hline Harvest aids application-SR & $22.73 \pm 1.56$ & $40.55 \pm 1.94$ & $1.84 \pm 0.53$ \\
\hline \multicolumn{4}{|c|}{ Site V } \\
\hline Droplet measurement & $24.53 \pm 2.54$ & $37.65 \pm 2.08$ & $1.16 \pm 0.79$ \\
\hline Harvest aids application-FR & $26.33 \pm 1.42$ & $45.55 \pm 2.69$ & $1.24 \pm 0.91$ \\
\hline
\end{tabular}

Note: FR: first-round; SR: second-round; the data in the table are mean \pm SD.

\subsection{Experimental design}

Droplet penetration in the canopy can be altered by changing spraying volume ${ }^{[24]}$. Following the results in $\mathrm{Ma}$ et al. ${ }^{[22]}$ and Meng et al. ${ }^{[14]}$, a spaying volume of more than $18 \mathrm{~L} / \mathrm{hm}^{2}$ yields an optimal defoliation efficacy by low-volume UAV spraying. In the present study, a spraying volume of $18 \mathrm{~L} / \mathrm{hm}^{2}$ and $22.5 \mathrm{~L} / \mathrm{hm}^{2}$ are respectively set to evaluate droplet coverage in the cotton canopy at different flight velocities and nozzle flow rates (Table 3) before harvest aid application in Site I and Site II in 2017. To identify the spraying parameters attributed to larger droplet coverage, some tests are performed to collect droplet coverage (measured in a $100 \mathrm{~m} \times 100 \mathrm{~m}$ square cotton field) for the two spraying volumes and that yielding a larger coverage is formally adopted in the experiments for harvest aid application on the cotton crops.

Table 3 Flight velocities and spraying volumes for optimizing the spraying volume of UAV 3WQFTX-10 in Site I and Site II in 2017

\begin{tabular}{cccc}
\hline Treatment & $\begin{array}{c}\text { Total zozzle flow rate } \\
/ \mathrm{mL} \cdot \mathrm{s}^{-1}\end{array}$ & $\begin{array}{c}\text { Flight velocity } \\
/ \mathrm{m} \cdot \mathrm{s}^{-1}\end{array}$ & $\begin{array}{c}\text { Spraying volume } \\
/ \mathrm{L} \cdot \mathrm{hm}^{-2}\end{array}$ \\
\hline D1 & 1512 & 4.0 & 18.0 \\
D2 & 1653 & 3.5 & 22.5
\end{tabular}

Note: The flight height is $2 \mathrm{~m}$ above the cotton canopy; single spraying swath is $3.5 \mathrm{~m}$; nozzle type is hydraulic flat fan Lu120-015.

In Site I, Site III and Site IV, three UAV treatments and one tractor treatment with three replications in $200 \mathrm{~m} \times 100 \mathrm{~m}$ rectangle experimental fields are used for harvest aid application; two UAV treatments and one knapsack treatment with three replications in $125 \mathrm{~m} \times 100 \mathrm{~m}$ rectangle experimental fields are used in Site II and Site V.

\subsection{Data collection}

For droplet coverage measurement, WSP cards are placed in three layers (upper, middle and bottom) of the cotton canopy accordingly in three laterally oriented sampling lines with $20 \mathrm{~m}$ spacing; these lines are vertical to the UAV flight direction. In each line, three sampling points with $3.5 \mathrm{~m}$ interval are deployed in a four-spray swaths. Three WPS cards $(25 \mathrm{~mm} \times 75 \mathrm{~mm})$ are used in each sampling point, wherein the first WPS card is clipped to a leaf in the upper layer $(70 \mathrm{~cm}$ above the ground in Site I, Site III and Site IV; $110 \mathrm{~cm}$ above the ground in Site II and Site V), the second WPS card is placed in the middle layer $(50 \mathrm{~cm}$ above the ground in Site I, Site III and Site IV; $80 \mathrm{~cm}$ above the ground in Site II and Site V), and the third WPS card is attached in the bottom layer ( $30 \mathrm{~cm}$ above the ground in Site I, Site III and Site IV; $40 \mathrm{~cm}$ above the ground in Site II and Site V) (Figure 2).
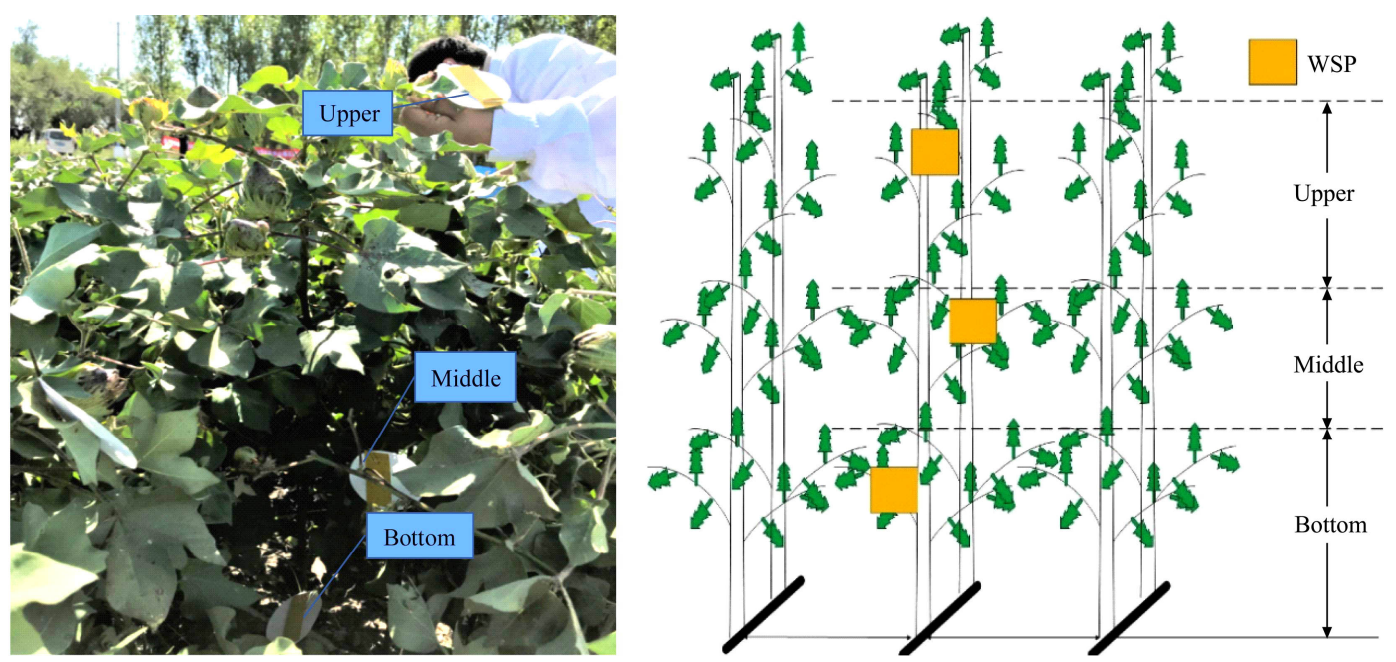

Figure 2 The placements of WSP cards in cotton canopy

For each replication of a treatment, five sampling points are randomly selected to evaluate the defoliation efficacy and boll opening rate. For each sampling point, 10 randomly selected cotton plants are tagged to count total bolls, opened bolls and green leaves before and after the spraying on the investigation days. Lint cotton yield and fiber quality are evaluated at the end of field experiments at each site based on the selected cotton plants.

\subsubsection{Determination of optimal operational parameters}

Droplet coverage is an important metric to evaluate the droplet deposition quality ${ }^{[25]}$. Two treatments (D1 and D2) are used to evaluate the droplet coverage (Table 3) and optimal operational parameters are determined based on the treatment yielding larger droplet coverage. To achieve a UAV spraying volume target, the nozzle flow rate and flight velocity are adjusted as illustrated in 
Table 3. First, water is used instead of pesticide to measure the droplet coverage rate in different cotton canopy layers, and each treatment is repeated three times. The WSP cards are carefully collected with tweezers approximately $10 \mathrm{~min}$ after the UAV spraying, and immediately placed inside a marked Kraft paper envelope for further assessment. In the indoor lab, DepositScan program (USDA, USA) is used to analyze droplet coverage after WPS cards are scanned by an HP scanner (HP Scanjet G4050). The analyzed zone on the WSP cards is randomly selected in the program as the ratio of the pixel number of the droplets covered yields the coverage ${ }^{[26]}$ according to the following equation:

$$
R(k)=\frac{\sum_{x=0}^{x-1} \sum_{y=0}^{y-1} g(k, x, y)}{\sum_{l=1}^{a} \sum_{x=0}^{X-1} \sum_{y=0}^{Y-1} g(l, x, y)}
$$

where, $R(k)$ is the ratio of the pixel number of the droplets in layer $k$ (i.e., upper, middle or bottom layer); $x$ and $y$ are coordinates of a pixel in horizontal plane and $g(k, x, y)=1$ if the color of $(x, y)$ in layer $\mathrm{k}$ is gray.

\subsubsection{Defoliation efficacy}

In both 2017 and 2018 field experiments, the green leaves of the tagged cotton plants are counted before and after harvest aid application on $0,7,14$ and 21 DAT according to the field efficacy trials criteria ${ }^{[27]}$. The defoliation rate is calculated by the following equation:

$$
R_{\mathrm{DE}}=\frac{N_{\mathrm{BS}}-N_{\mathrm{AS}}}{N_{\mathrm{BS}}} \times 100 \%
$$

where, $R_{\mathrm{DE}}$ is the defoliation rate; $N_{\mathrm{BS}}$ is the number of green leaves before treatment and $N_{\mathrm{AS}}$ is the number of remaining green leaves after treatment.

\subsubsection{Boll opening rate}

In both 2017 and 2018 field experiments, the total bolls and opened bolls of the labeled plants are counted before treatment (0 DAT), and the opened bolls are accordingly counted after harvest aid application on 7,14 and 21 DAT. The boll opening rate is assessed using the following equation:

$$
R_{\mathrm{BO}}=\frac{N_{\mathrm{OB}}}{N_{\mathrm{TB}}} \times 100 \%
$$

where, $R_{\mathrm{BO}}$ is the boll opening rate; $N_{\mathrm{OB}}$ is the number of opened bolls and $N_{\mathrm{TB}}$ is the total number of bolls of the labeled plants in each replication of each treatment.

2.6.4 Lint cotton yield and fiber quality

Lint cotton yield and fiber quality are evaluated at the end of field experiments in 2017 and 2018. The yield of lint cotton is calculated according to the equation below:

$$
Y_{\mathrm{LC}}+N_{B} \times W \times L P, L P=\frac{\text { lint }}{\text { seed cotton }}, \mathrm{w} / \mathrm{w}
$$

where, $Y_{\mathrm{LC}}$ is yield of lint cotton in each treatment; $N_{B}$ is the number of bolls in the treatment; $W$ is the weight of a single boll and $L P$ is the lint percentage. In this work, the single boll weight and lint percentage are assessed at the end of the field experiment.

The fiber length, fiber tenacity and Micronair value are measured in every treatment to evaluate fiber quality. All the sampling bolls for measuring the fiber quality components and lint cotton yield are tested using the High-volume Instrument (HVI-900A, Uster, Knoxville, TN, USA) in the Cotton Quality Supervision, Inspection and Testing Center of the Ministry of Agriculture and Rural Affairs in Anyang, Henan Province.

\subsection{Data analysis}

The results are presented by experimental site, and the means are compared among the treatments in the same site using
Duncan's multiple range test at $p<0.05$ in SPSS 21.0 (Chicago, IL, USA).

\section{Results}

\subsection{Optimal operational parameters of UAV}

\subsubsection{Droplet distribution in cotton canopy of different layers}

Since high-density planting and thick leaves may block droplet penetration, the droplet deposition in three layers of the cotton canopy in two experimental sites (Site I and Site II) of 2017 is sampled in order to study droplet penetration for cotton plants. The data are presented by site and shown in Figure 3.
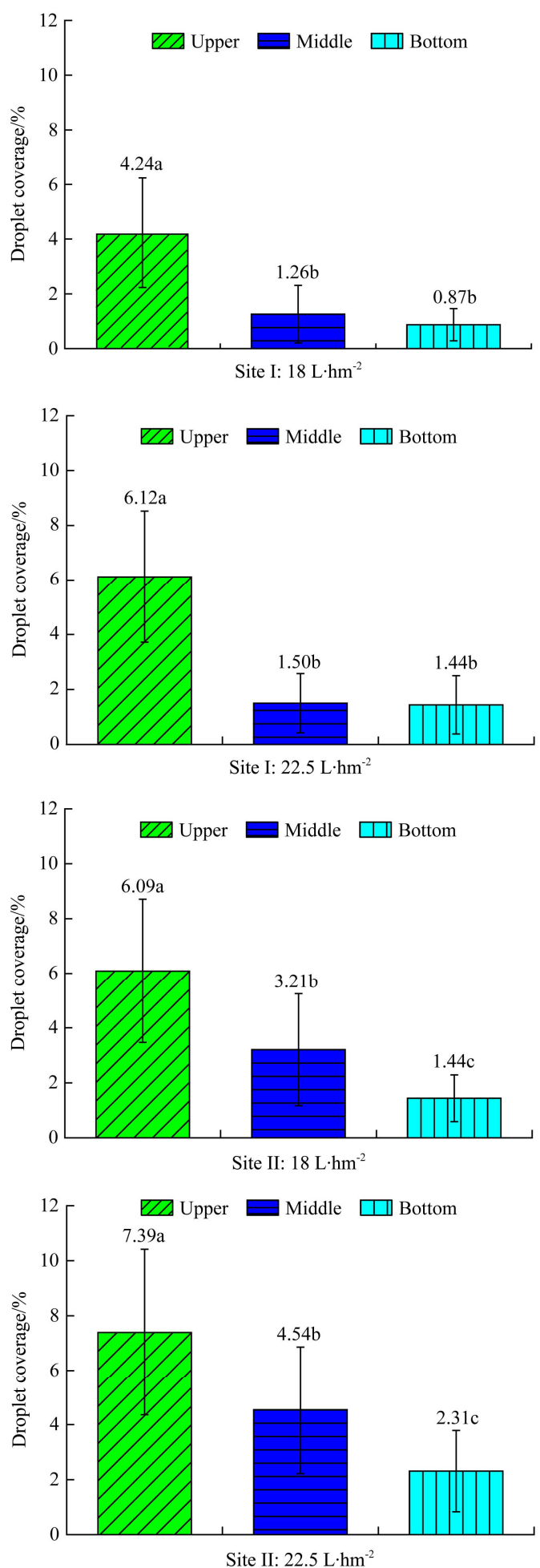

Figure 3 Droplet coverage of two spraying volumes in different layers of cotton canopy in two experimental sites in 2017 
Site I. As shown in Figure 3, with a spraying volume of $18 \mathrm{~L} / \mathrm{hm}^{2}$, the droplet coverage in the upper layer $(4.24 \%)$ is significantly larger than that of the middle $(1.26 \%)$ and bottom $(0.87 \%)$. There is no significant difference between the middle and bottom layers. When the spraying volume is increased to $22.5 \mathrm{~L} / \mathrm{hm}^{2}$, the droplet coverage of the upper canopy increased to $6.12 \%$, which is still significantly higher than that of the middle $(1.50 \%)$ and bottom $(1.44 \%)$, and still no significant difference is observed between middle and bottom layers.

Site II. As shown in Figure 3, the droplet coverage of the upper, middle and bottom is $6.09 \%, 3.21 \%$ and $1.44 \%$, respectively when the spraying volume is $18 \mathrm{~L} / \mathrm{ha}$, and $7.39 \%, 4.54 \%$ and $2.31 \%$, respectively when the spraying volume is $22.5 \mathrm{~L} / \mathrm{hm}^{2}$. Compared with the results in Site I, the droplet coverage is significantly different among the three layers in Site II due to its sparse planting density. Since the penetration of Site II is better and that of Site I, dual-round harvest application is used in Site I, Site III and Site IV, while single-round harvest application is used in Site II and Site V.

\subsubsection{Average droplet coverage in the whole cotton canopy}

Averaged across all treatments in each experimental site, the droplet coverage of the two spraying volumes $18 \mathrm{~L} / \mathrm{hm}^{2}$ and $22.5 \mathrm{~L} / \mathrm{hm}^{2}$ are $2.22 \%$ and $3.02 \%$, respectively, in Site I, and $3.58 \%$ and $4.74 \%$, respectively, in Site II (Figure 4). With the increased spraying volume, the droplet coverage of D2 $\left(22.5 \mathrm{~L} / \mathrm{hm}^{2}\right)$ is $36.04 \%$ and $34.40 \%$ larger than that of D1 $\left(18 \mathrm{~L} / \mathrm{hm}^{2}\right)$ in Site I and Site II, respectively.

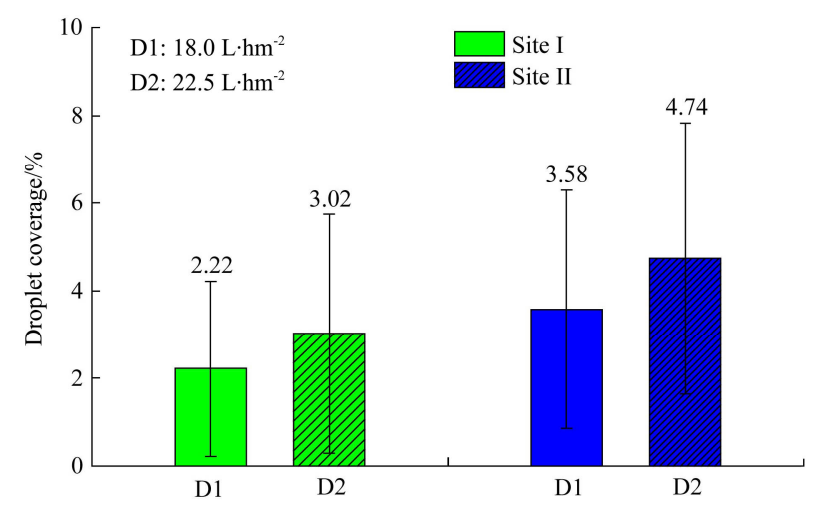

Figure 4 The average droplet coverages in cotton canopy in two experimental sites in 2017

Considering the droplet distribution in the cotton canopy and action mechanism of defoliants, increased droplet coverage sees an improved defoliation efficacy. However, a further increase in spraying volume leads to a significant operation efficiency degradation of UAV spraying. Considering the trade-off between droplet coverage and operation efficiency, the spraying volume is not further increased to pursue an even higher droplet coverage. Therefore, the operational parameters in the D2 treatment (spraying volume, $22.5 \mathrm{~L} / \mathrm{hm}^{2}$; flight velocity, $3.5 \mathrm{~m} / \mathrm{s}$; nozzle flow rate, $1.654 \mathrm{~L} / \mathrm{min}$ ) to spray harvest aids by UAV in all experimental sites are adopted.

\subsection{Effects of dosage and the application frequency on} defoliation efficacy

Site I (2017). In I-T1 (UAV treatment) and I-T4 (Tractor treatment), the recommended dosage is adopted and applied only once on 2 September 2017; in I-T2, dual-round application with an $80 \%$ of the recommended dosage for each round is adopted and sprayings are conducted on 2 September 2017 and 9 September 2017, while in I-T3 the same spraying methodology is adopted as in I-T2 except that the recommended dosage used in each round is adopted (Table 1). As shown in Figure 5, the defoliation rates of four treatments are $68.94 \%$ (I-T1), 64.78\% (I-T2), 67.55\% (I-T3) and $71.82 \%$ (I-T4) on 7 DAT; these rates increase over time, in both single- and dual-round application treatments. However, on 14 DAT, the defoliation rates of I-T2 (25.67\%) and I-T3 (24.01\%) increase much faster than those of I-T1(16.52\%) and I-T4 (16.82\%). On 21 DAT, the defoliation rates of I-T2 (97.02\%) and I-T3 $(97.47 \%)$ already meet the machine harvesting requirements (i.e., a defoliation rate of $\geq 95 \%$ ), while that of I-T1 $(88.76 \%$ ) and I-T4 (92.21\%) failed to meet the requirements.

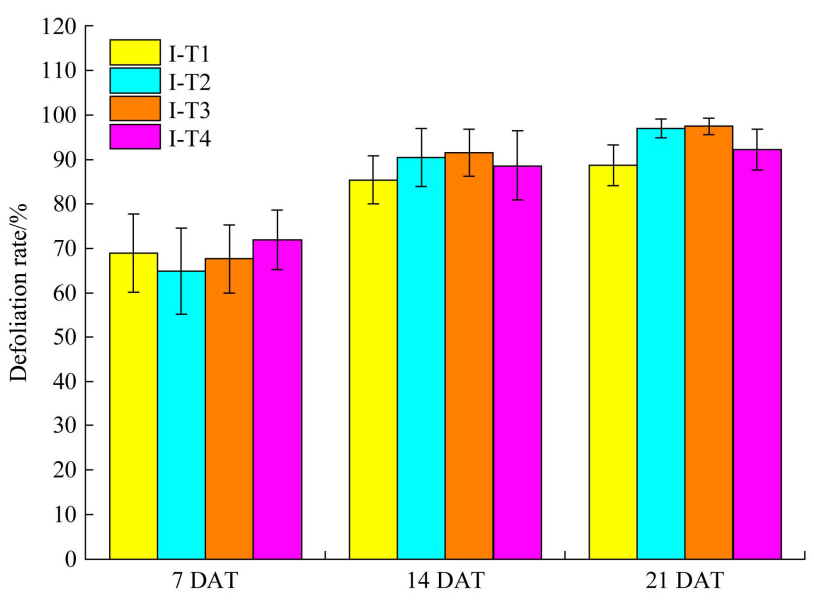

Figure 5 Defoliation rates of four treatments in Site I

(DAT: days after treatment)

Site II (2017). Based on the droplet distribution of Site II and due to its sparse cotton plants, the harvest aids are only applied in a single-round on 20 September 2017. The recommended dosage of harvest aids is applied in II-T1 (UAV treatment) and II-T3 (knapsack treatment), while $80 \%$ of the recommended dosage is applied in II-T2. As illustrated in Figure 6, the defoliation rates of II-T1 on the three investigating dates are $68.44 \%$ (7 DAT), $87.56 \%$ (14 DAT) and $96.32 \%$ (21DAT). Correspondingly, using the same dosage, the defoliation rates of II-T3 are $57.46 \%$ (7 DAT), $75.47 \%$ (14 DAT) and $85.67 \%$ (21 DAT). After a $20 \%$ reduction in the recommended dosage, the defoliation rates of II-T2 are $63.45 \%$ (7 DAT), $78.29 \%$ (14 DAT) and $88.43 \%$ (21 DAT). The 21 DAT defoliation rates of II-T2 and II-T3 do not meet the requirements.

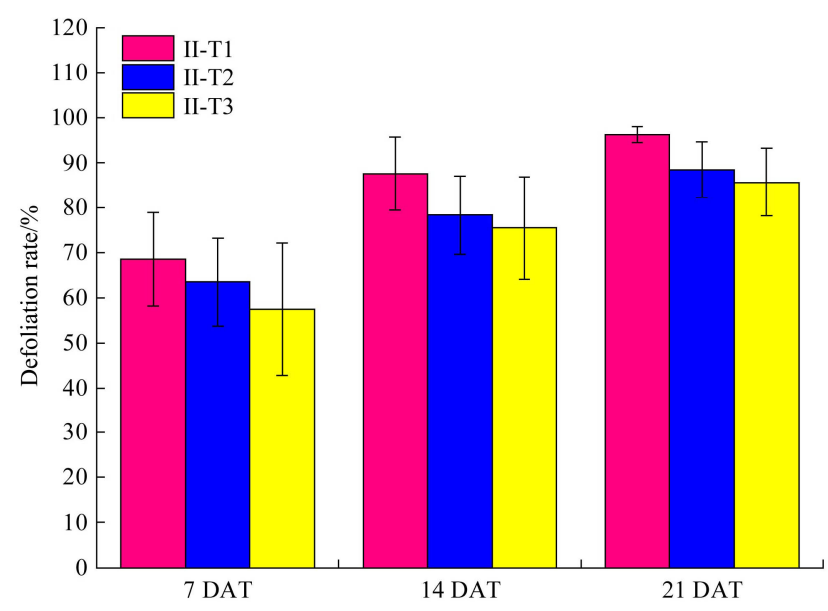

Figure 6 Defoliation rates of three treatments in Site II (DAT: days after treatment)

Site III (2018). The same treatment arrangement is adopted in Site III as is in Site I. As illustrated in Figure 7, averaged across 
all treatments, the defoliation rates on 7, 14 and 21 DAT are $57.42 \%, 92.31 \%$ and $95.87 \%$, respectively. On 14 DAT, $85.23 \%$ and $88.72 \%$ of the leaves fall off the cotton plants in III-T1 and III-T4, respectively. The respective defoliation rates of 21 DAT are only $91.84 \%$ and $93.95 \%$, which fail to meet the mechanical harvest requirement. The defoliation rates of III-T2 are $54.44 \%$ (7 DAT), 98.68\% (14 DAT) and 99.87\% (21 DAT), and correspondingly $63.33 \%, 99.05 \%$ and $99.59 \%$ in the III-T3 treatment, respectively. The achieved defoliation rates in III-T2 and V-T3 on 21 DAT meet the mechanical harvest requirements.

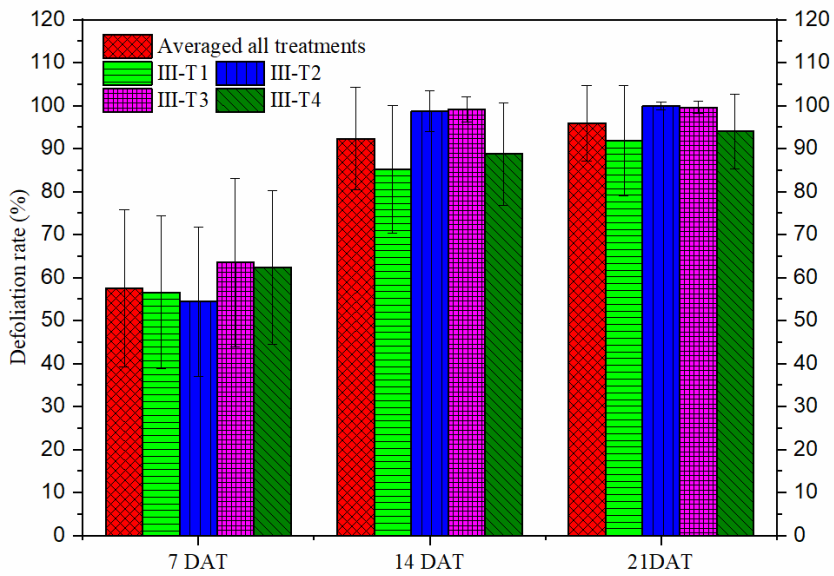

Figure 7 Defoliation rates of four treatments Site III (DAT: days after treatment)

Site IV (2018). The treatment arrangement of Site IV is the same as that in Site I and Site III except the date of spraying. In Site IV, the first-round of harvest aid spraying is conducted on 6 September 2018, while for treatments IV-T2 and IV-T3, the second-round application is conducted on 14 September 2018. As illustrated in Figure 8, averaged across all treatments, the defoliation rates are 68.23\% (7 DAT), 92.33\% (14 DAT) and $96.20 \%$ (21 DAT). The defoliation rates of IV-T1 is $67.06 \%$ (7 DAT), 82.82\% (14 DAT) and 91.53\% (21 DAT), and correspondingly $63.10 \%, 92.56 \%$ and $94.13 \%$ in treatment IV-T4. If the harvest aids are applied only once, the defoliation rates on 21 DAT could not meet the requirements in either the low volume (UAV treatment) application or the high volume (Tractor treatment) application. For treatments with dual-round application, the defoliation rates on 14 DAT are $96.55 \%$ (IV-T2) and 98.13\% (IV-T3), which successfully meet the defoliation requirements of the machine harvest. Therefore, it is feasible to use the recommended dosage of harvest aids with a $20 \%$ reduction for dual-round of application by UAV with low-volume spraying.

Site V (2018). The treatment arrangements of Site V are the same as Site II. As illustrated in Figure 9, the defoliation rates of V-T1 are $71.62 \%$ (7 DAT), $88.05 \%$ (14 DAT) and 97.96\% (21 DAT), and correspondingly $62.27 \%, 82.95 \%$ and $91.98 \%$ in V-T2, and $59.39 \%, 78.39 \%$ and $93.33 \%$ in V-T3, respectively. For low-volume UAV application, if the harvest aids are only applied once, a reduction of $20 \%$ of the recommended dosage is infeasible to meet the requirements of mechanical harvest.

In summary, in high-density cotton areas of Site I, Site III and Site IV where harvest aids are applied only once, the defoliation rates on 21 DAT fail to meet the requirements with the recommended dosage no matter using the UAV or tractor. However, although $20 \%$ of the recommended dosage of harvest aids have been reduced, a dual-round application with a 7-day interval could meet the defoliation requirement for mechanical harvest on 21 DAT. From the perspective of environmental protection and cotton production cost, a dual-round application with $80 \%$ recommended dosage of harvest aids in each round could be employed in high-density cotton production areas.

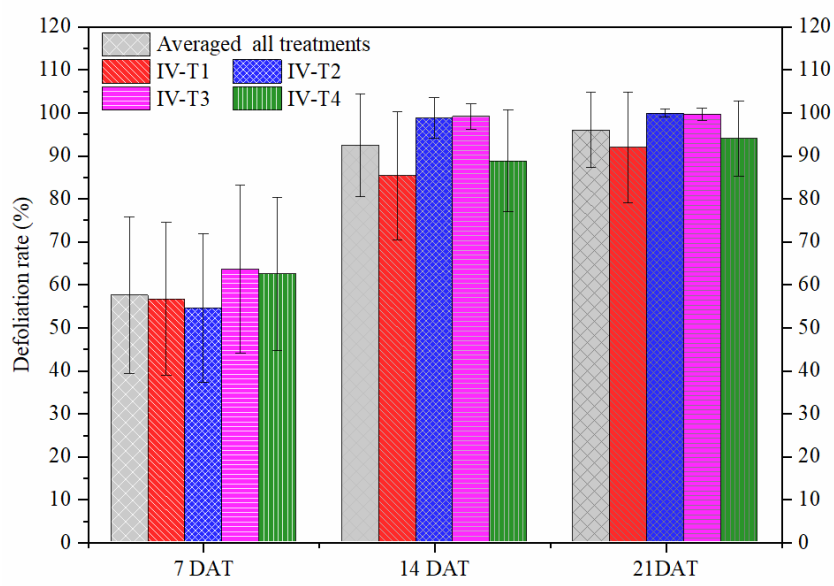

Figure 8 Defoliation rates of four treatments in Site IV (DAT: days after treatment)

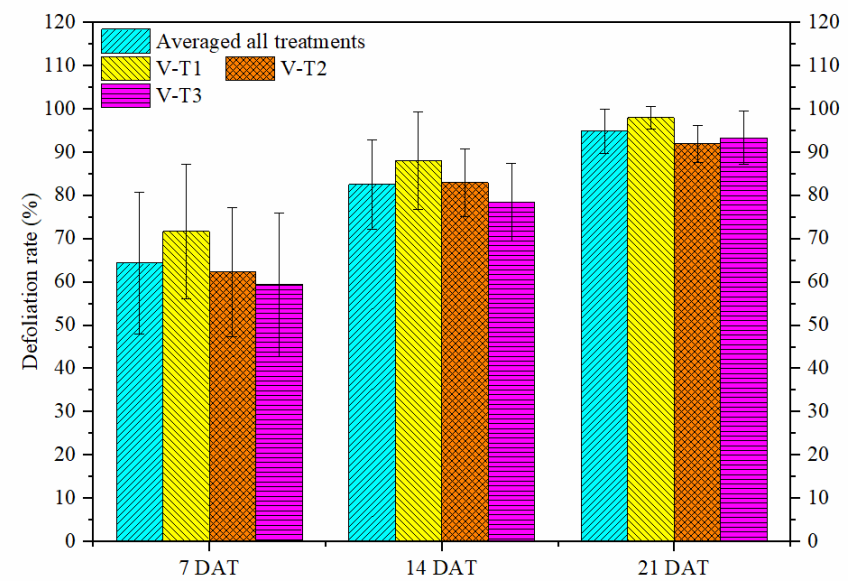

Figure 9 Defoliation rates of three treatments in Site V (DAT: days after treatment)

In Site II and Site V, harvest-aid application by the UAV with the recommended dosage is the preferred choice to limit pesticide use and save operation cost. For the knapsack treatment, the defoliation on 21 DAT fail to meet the requirement; this observation may be due to pesticide waste and the uneven distribution of droplets by manual knapsack spraying.

\subsection{Effect of dosage and the application frequency on boll opening rate}

Site I (2017). As shown in Figure 10, the initial boll opening rates (0 DAT) of four treatments are within $35.55 \%-39.64 \%$. On 7 DAT, $63.56 \%-72.34 \%$ of the bolls open in four treatments, where I-T4 (72.34\%) has the highest boll opening rate while I-T3 (63.56\%) has the lowest boll opening rate. With the second-round spraying, the boll opening rates on 14 DAT are $88.76 \%$ (I-T2) and $90.87 \%$ (I-T3), and correspondingly $93.65 \%$ and $95.66 \%$ on 21 DAT. For the treatments of I-T1 and I-T4, the boll opening rates on 21 DAT are $86.95 \%$ and $88.65 \%$, respectively, which fail to meet the requirements.

Site II (2017). As shown in Figure 11, the initial boll opening rate (0 DAT) is within $58.21 \%-63.14 \%$, the 7 DAT boll opening rates are $88.91 \%$ (II-T1), $85.21 \%$ (II-T2) and $83.35 \%$ (II-T3). The 14 DAT boll opening rates of II-T1(95.67\%) and II-T3 
(91.47\%) are more than $90 \%$, while that of II-T2 is $89.55 \%$. Another 7 days later, the boll opening rates of all three treatments meet the machine harvesting requirement, of which, II-T1 (100\%) achieves the highest boll opening rate, and II-T2 (93.44\%) achieved the lowest one.

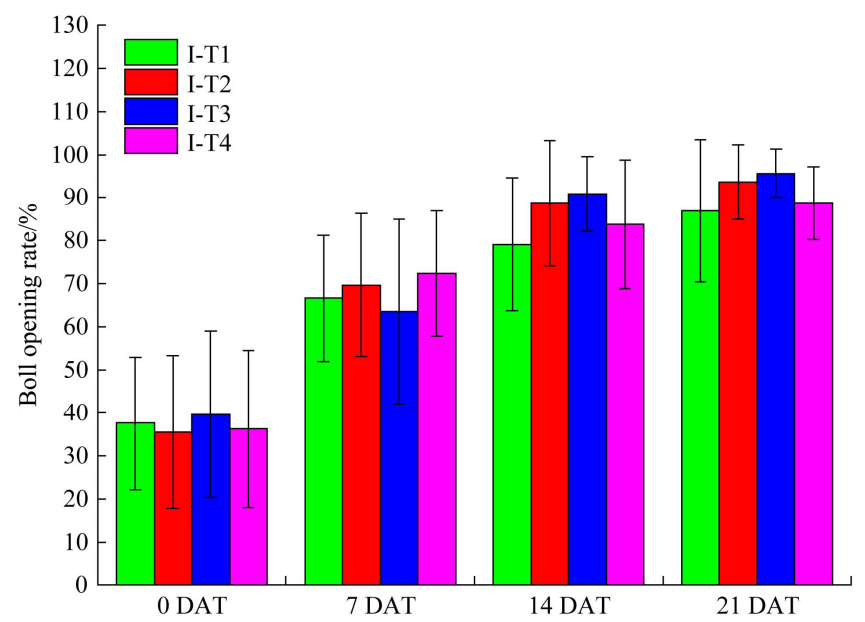

Figure 10 Boll opening rates in four treatments in site I (DAT: days after treatment)

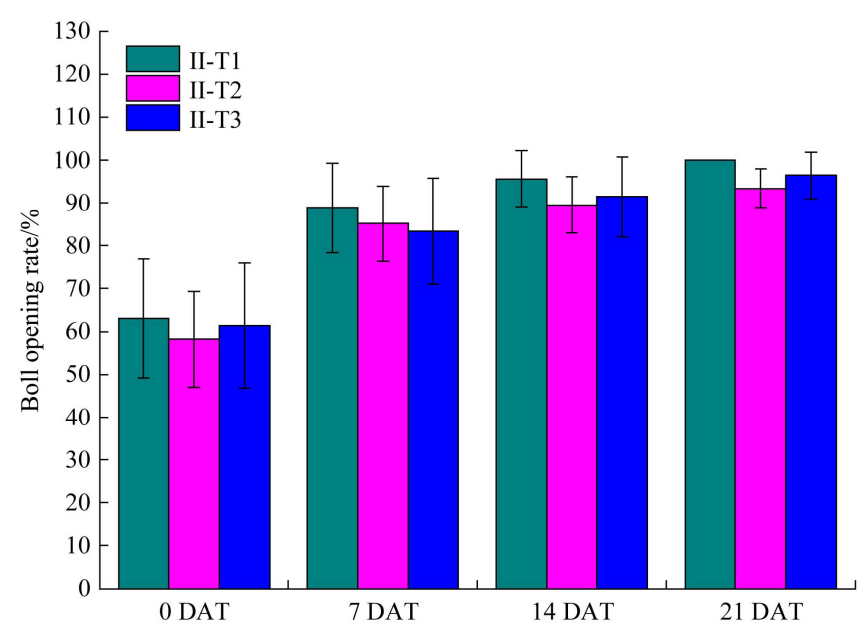

Figure 11 Boll opening rates in three treatments in site II (DAT: days after treatment)

Site III (2018). As illustrated in Figure 12, averaged across all treatments, the initial boll opening rate (0 DAT) is $36.47 \%$, and the boll opening rates on 7 DAT, 14 DAT and 21 DAT are $64.32 \%$, $87.90 \%$ and $93.64 \%$, respectively. The boll opening rates of III-T1 is $64.59 \%$ (7 DAT), $82.10 \%$ (14 DAT) and $87.90 \%$ (21 DAT), while those of III-T4 are $64.79 \%$ (7 DAT), $86.48 \%$ (14 DAT) and 91.98\% (21 DAT), respectively. The boll opening rate of III-T4 on 21 DAT meets the requirement of machine harvest, but that of III-T1 fails to meet the requirement. The reason for that failure may be due to the initial boll opening rate of III-T1 $(33.49 \%)$ being clearly lower than that of III-T4 (43.66\%). A dual-round harvest aid application is conducted in III-T2 and III-T3 treatments, but the dosage of III-T2 is $20 \%$ less than that of III-T3. The boll opening rate on 21 DAT is $94.61 \%$ (III-T2) and $98.62 \%$ (III-T3), which meet the boll opening rate requirement of machine harvest.

Site IV (2018). It could be seen from the Figure 13, averaged across all treatments, the initial boll opening rate (0 DAT) is $34.01 \%$, and the boll opening rates on 7, 14 and 21 DAT are $59.86 \%, 90.00 \%$ and $95.25 \%$, respectively. Although the harvest aids are only applied once in treatment IV-T1, the initial boll opening rate is $41.12 \%$ which increases to $93.81 \%$ on 21 DAT; this meets the boll opening rate requirement for the machine harvest. The results of IV-T1 are in accordance with III-T4 wherein the initial boll opening rate and 21 DAT boll opening rate of IV-T4 are $32.32 \%$ and $88.32 \%$, respectively, which fail to meet the machine harvest requirement. For the dual-round application treatments, the boll opening rate on 21 DAT of IV-T2 and IV-T3 are $98.62 \%$ and $98.18 \%$, respectively, which meet the boll opening rate requirement for machine harvest.

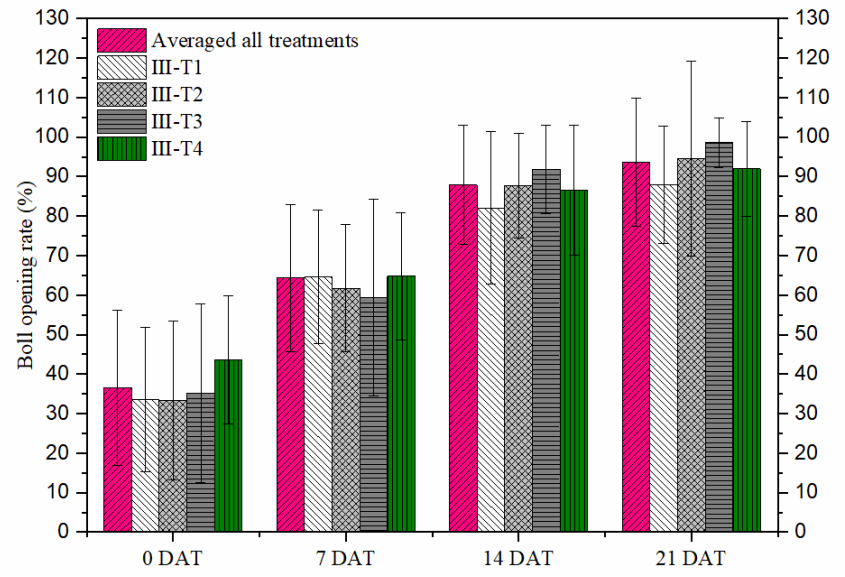

Figure 12 Boll opening rates in four treatments in site III (DAT: days after treatment)

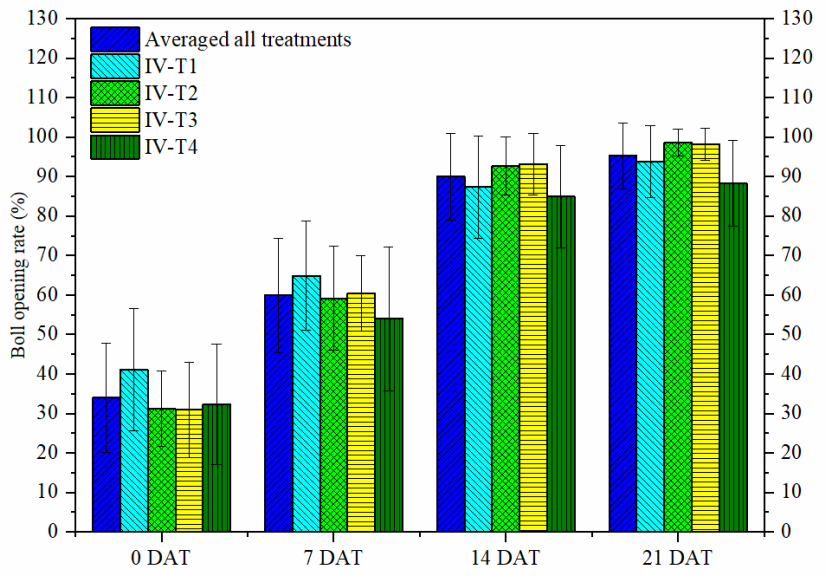

Figure 13 Boll opening rates in four treatments in Site IV (DAT: days after treatment)

Site V (2018). Averaged across all the treatments, the initial boll opening rate and 21 DAT boll opening rate are $51.92 \%$ and 94.55\%, respectively (Figure 14). For low-volume UAV application (V-T1) or high-volume knapsack application (V-T3) wherein the recommended dosage is applied, the 21 DAT boll opening rates $(99.32 \%$ and $97.41 \%$, respectively) meet the boll opening requirement. Although the initial boll opening rate of V-T2 is $52.97 \%$, the achieved boll opening rate of V-T2 on 21 DAT $(88.39 \%)$ fails to meet the requirement when the harvest aid application dosage is reduced by $20 \%$; this finding means that a $20 \%$ decrease of the dosage in this case is not preferred.

Concluding from the data in five experimental sites, a dual-round application of harvest aids with a $20 \%$ reduction in its recommended dosages by low-volume UAV spraying is encouraged in high-density planting areas $\left(180,000-195,000\right.$ plants $\left./ \mathrm{hm}^{2}\right)$ to meet both requirements of the defoliation and boll opening rates for mechanical harvesting. In sparse planting areas $\left(\leq 90,000 \mathrm{plants} / \mathrm{hm}^{2}\right)$, a single application of harvest aids at the recommended dosage by low-volume UAV spraying is encouraged. 


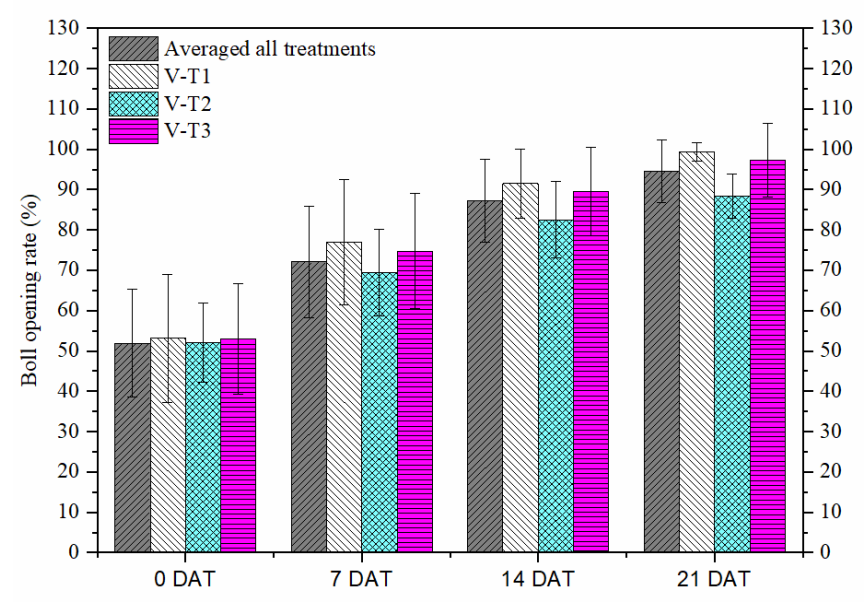

Figure 14 Boll opening rates in three treatments in site $\mathrm{V}$

(DAT: days after treatment)

3.4 Effects of dosage and the application frequency on fiber quality and lint cotton yield

As presented in Table 4, there are no significant differences among all treatments in the five experimental sites with respect to the values of fiber length, fiber strength and Micronair. For lint cotton yield, no significant difference is observed in single boll weight and lint percentage. It is observed that the harvest aid dosage and the application frequency by low-volume UAV spraying and traditional high-volume ground-based sprayers do not affect lint cotton yield and fiber quality.

Table 4 Effect of harvest-aid dosage and the number of application rounds on fiber quality and lint cotton yield components in five experimental sites

\begin{tabular}{|c|c|c|c|c|c|}
\hline Treatment & $\begin{array}{l}\text { Fiber } \\
\text { length } \\
/ \mathrm{mm}\end{array}$ & $\begin{array}{c}\text { Fiber } \\
\text { strength } \\
(\mathrm{cN} / \text { tex) }\end{array}$ & $\begin{array}{l}\text { Micronaire } \\
\text { value }\end{array}$ & $\begin{array}{c}\text { Boll } \\
\text { weight } \\
/ \mathrm{g} \cdot \text { boll }^{-1}\end{array}$ & $\begin{array}{c}\text { Lint } \\
\text { percentage } \\
\quad / \%\end{array}$ \\
\hline \multicolumn{6}{|c|}{ Site I } \\
\hline I-T1 & $29.67 \mathrm{a}$ & $28.71 \mathrm{a}$ & $5.22 \mathrm{a}$ & $5.58 \mathrm{a}$ & $45.45 \mathrm{a}$ \\
\hline $\mathrm{I}-\mathrm{T} 2$ & $28.97 \mathrm{a}$ & $29.08 \mathrm{a}$ & $5.15 \mathrm{a}$ & $5.37 \mathrm{a}$ & $44.77 \mathrm{a}$ \\
\hline $\mathrm{I}-\mathrm{T} 3$ & $29.56 \mathrm{a}$ & $28.56 \mathrm{a}$ & $4.95 \mathrm{a}$ & $5.45 \mathrm{a}$ & $46.32 \mathrm{a}$ \\
\hline $\mathrm{I}-\mathrm{T} 4$ & $31.00 \mathrm{a}$ & $29.39 \mathrm{a}$ & $5.00 \mathrm{a}$ & $5.66 \mathrm{a}$ & $46.23 \mathrm{a}$ \\
\hline \multicolumn{6}{|c|}{ Site II } \\
\hline II-T1 & $28.21 \mathrm{a}$ & $26.90 \mathrm{a}$ & $5.65 \mathrm{a}$ & $6.04 \mathrm{a}$ & $39.63 a$ \\
\hline II-T2 & $27.93 \mathrm{a}$ & $27.88 \mathrm{a}$ & $5.60 \mathrm{a}$ & $6.21 \mathrm{a}$ & $40.11 \mathrm{a}$ \\
\hline II-T3 & $29.00 \mathrm{a}$ & $28.00 \mathrm{a}$ & $5.43 \mathrm{a}$ & $5.98 \mathrm{a}$ & $38.45 \mathrm{a}$ \\
\hline \multicolumn{6}{|c|}{ Site III } \\
\hline I-T1 & $29.22 \mathrm{a}$ & $28.51 \mathrm{a}$ & $5.10 \mathrm{a}$ & $5.28 \mathrm{a}$ & $47.86 \mathrm{a}$ \\
\hline $\mathrm{I}-\mathrm{T} 2$ & $28.90 \mathrm{a}$ & $28.68 \mathrm{a}$ & $4.95 \mathrm{a}$ & $5.30 \mathrm{a}$ & $45.89 \mathrm{a}$ \\
\hline $\mathrm{I}-\mathrm{T} 3$ & $29.48 \mathrm{a}$ & $28.71 \mathrm{a}$ & $5.05 \mathrm{a}$ & $5.38 \mathrm{a}$ & $46.02 \mathrm{a}$ \\
\hline $\mathrm{I}-\mathrm{T} 4$ & $30.04 \mathrm{a}$ & $29.48 \mathrm{a}$ & $4.98 \mathrm{a}$ & $5.46 \mathrm{a}$ & $46.50 \mathrm{a}$ \\
\hline \multicolumn{6}{|c|}{ Site IV } \\
\hline II-T1 & $29.14 \mathrm{a}$ & $28.24 \mathrm{a}$ & $5.10 \mathrm{a}$ & $5.32 \mathrm{a}$ & $47.56 \mathrm{a}$ \\
\hline II-T2 & $28.84 \mathrm{a}$ & $28.56 \mathrm{a}$ & $4.88 \mathrm{a}$ & $5.03 \mathrm{a}$ & $47.20 \mathrm{a}$ \\
\hline II-T3 & $29.36 \mathrm{a}$ & $28.20 \mathrm{a}$ & $4.94 \mathrm{a}$ & $5.36 \mathrm{a}$ & $46.17 \mathrm{a}$ \\
\hline II-T4 & $29.03 \mathrm{a}$ & $29.23 a$ & $4.85 \mathrm{a}$ & $5.34 \mathrm{a}$ & $47.49 \mathrm{a}$ \\
\hline \multicolumn{6}{|c|}{ Sinte V } \\
\hline III-T1 & $27.85 a$ & $28.20 \mathrm{a}$ & $5.83 \mathrm{a}$ & $5.14 \mathrm{a}$ & $41.14 \mathrm{a}$ \\
\hline III-T2 & $27.43 a$ & $27.28 \mathrm{a}$ & $5.84 \mathrm{a}$ & $5.21 \mathrm{a}$ & $40.39 \mathrm{a}$ \\
\hline III-T3 & $27.53 \mathrm{a}$ & $28.38 \mathrm{a}$ & $5.83 \mathrm{a}$ & $5.57 \mathrm{a}$ & $40.67 \mathrm{a}$ \\
\hline
\end{tabular}

Note: The same lowercase letter means no significant difference at $p<0.05$ in the same column within all treatments in each experimental site.

\section{Discussion}

This work has derived a new method for harvest-aid application by plant protection UAV utilizing low-volume spraying via evaluating the effects of dosage and the application frequency on defoliation rate, boll opening rate, lint yield and fiber quality. Under the dual-round strategy, harvest aid application on cotton by UAVs could help to reduce $20 \%$ of the recommended dosage due to the high-concentration and low-volume spraying by UAVs in high-density cultivation areas. In sparse density cultivation areas, it is enough to apply harvest aids only once by UAV.

Because most harvest aids have good osmotic effects but no inner-absorption conductive effects, they must make active contact to hasten boll maturity and leaf defoliation. A previous study has shown a close relationship between defoliation efficacy and spraying volume, when using either hormonal or herbicidal harvest aids, the defoliation rate increases with increased spraying volume ${ }^{[28]}$. To obtain a preferred defoliation efficacy and boll opening rate, high-quality spraying in the cotton canopy is needed for harvest aid application. In China, to meet the requirements of spraying quality, ground-based sprayers usually need a spraying volume of $450-750 \mathrm{~L} / \mathrm{hm}^{2}$ for a substantial "shower" spraying to guarantee the leaves on the whole canopy are covered by droplets; in addition, a dual-round application is required in high-density

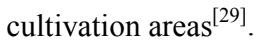

In the previous field research of harvest aid application by ground-based sprayer using a high-volume spraying method that compares the treatments with single-round application of harvest aids, the defoliation rate $(96.7 \%)$ and boll opening rate $(98.3 \%)$ on 18 DAT improve with the dual-round application of harvest aid with a 6-day interval; there is no significant difference with the treatments applied in three-rounds with 4-day interval ${ }^{[30]}$. In the field research of harvest aids applied by UAVs with a low-volume and high-concentration spraying method, the defoliation rate and boll opening rate on 20 DAT are $91.5 \%$ and $89.4 \%$, respectively, when the harvest aids are applied in a single-round in the Xinjiang high-density planting area ${ }^{[21]}$.

Boll opening chemicals are used to facilitate boll opening and the potential for a single crop harvest by enhancing the opening of green bolls on the cotton plant based on the boll population in various stages of maturity. Ethephon is widely used as a cotton harvest aid and can effectively increase the percentage of open bolls ${ }^{[31]}$. Some researchers show that defoliant dosage does not show a significant difference on the boll opening rate, but defoliant mixed with boll opener could increase the percentage of the boll opening rate ${ }^{[32,33]}$. However, some research shows that the dosage of defoliant mixed with boll opener does not significantly influence the defoliation rate and rather has a light influence on the boll opening rate ${ }^{[7]}$. The reason for this may be the difference between the initial boll opening rate and the boll opener dosage. This research shows that for a single-round application of the recommended dosage whether by a low-volume UAV or by a high-volume tractor spraying, the high-density planting areas (Site I, Site III and Site IV) result in boll opening rates of III-T4 (91.98\%) and IV-T1 $(93.81 \%)$ on 21 DAT, which meet the boll opening rate requirement of machine harvest, but that of III-T1 $(87.90 \%)$ and IV-T4 $(88.32 \%)$ fail to meet the requirement. The initial boll opening rates of III-T1 $(33.49 \%)$ and IV-T4 $(32.32 \%)$ are less than $35 \%$, while that of III-T4 (43.66\%) and IV-T1 $(41.12 \%)$ are more than $40 \%$. With the dual-round application strategy, the boll opening rates of the treatments of both the recommended dosage 
and $80 \%$ of the recommended dosage meet the requirements, and no significant difference is observed. In sparse density planting areas (Site II and Site V) utilizing the single-round harvest aid application strategy, the boll opening rates of treatment with recommended dosage (V-T1, 99.32\%; V-T3, 97.41\%; II-T1, $100.00 \%$; II-T3, $96.43 \%$ ) are significantly higher than that of the treatment with $80 \%$ of the recommended dosage (V-T2, 88.39\%) on 21 DAT, However, though with the $80 \%$ of the recommended dosage, the 21 DAT boll open rate of II-T2 (93.44\%) met the requirement. The initial boll opening rates of the three treatments in Site V are $52.07 \%-53.15 \%$, while these of the three treatments in Site II are $58.21 \%-63.14 \%$. Therefore, the differences of initial boll opening rates among the three treatments in each experimental site are related to harvest aid dosage. With different initial boll opening rates and plant densities, likely harvest-aid dosage following the application frequency should be considered when using harvest aids that consist of defoliant and boll opener.

It is observed that harvest-aid chemicals do not have a negative influence on fiber quality ${ }^{[34]}$. UAVs applying harvest aids with low-volume and high-concentration spraying does not affect the fiber quality and cotton yield $d^{[14,22,23]}$. However, there are very few related reports on the effects of harvest aid dosage and the application frequency on cotton yield and fiber quality by low-volume UAV spraying. In this study, compared with the conventional high-volume and low-concentration spraying method, it is found that harvest aid dosage and the applications frequency by UAVs utilizing a low-volume and high-concentration spraying method do not affect lint cotton yield and fiber quality. The results of the effect of dosage on fiber quality and cotton yield are consistent with previous research by Xin et al. ${ }^{[23]}$.

Although this study is carried out in five experimental field sites covering two cultivation modes in China, more knowledge is needed to fully understand the harvest-aid dosage and the application frequency on different cultivation modes and environmental conditions. For UAVs applying harvest aids for harvesting preparation, there are still certain aspects requiring further investigation in high-density cultivation areas for future work. These areas include the following: (1) Single-round application with higher volume (more than $22.5 \mathrm{~L} / \mathrm{hm}^{2}$ ) that may result in larger droplet coverage should be considered. (2) Dual-round application with different dosages between rounds could be tried. (3) Dual-round application with different volumes between rounds could be tried.

\section{Conclusions}

According to the droplet coverage evaluated in two cultivation modes (Site I and Site II), the appropriate operational parameters of low-volume UAV spraying for harvest aid application before mechanical harvest is determined to be the following: a spraying volume of $22.5 \mathrm{~L} / \mathrm{hm}^{2}$, a flight velocity of $3.5 \mathrm{~m} / \mathrm{s}$ and a total nozzle flow rate of $1.654 \mathrm{~L} / \mathrm{min}$ (D2). Based on the optimal operating parameters of UAVs, the dosage and application rounds of harvest aids are adjusted according to the cotton plant density in five experimental sites in China; the tractor and knapsack treatments are set as reference cases, and the results show that:

1) In the Yellow River valley region with sparse-density cultivation mode $(\leq 90,000$ plants/ha), it is feasible to apply single-round harvest aids with the recommended dosage (i.e., defoliant: $540 \mathrm{~g} / \mathrm{L}$ thidiazuron and diuron SC $180 \mathrm{~mL} / \mathrm{ha}$; boll opener: $400 \mathrm{~g} / \mathrm{L}$ Ethephon AS $1050 \mathrm{~mL} / \mathrm{ha}$; spray adjuvant: $280 \mathrm{~g} / \mathrm{L}$ alkyl-ethyl-sulfonate adjuvant $900 \mathrm{~mL} / \mathrm{hm}^{2}$ ) to meet the requirements of the defoliation and boll opening rates for mechanical harvest (II-T1 and V-T1).

2) In the northwestern inland cotton region with a high-density cultivation mode $(180,000 \sim 195,000$ plants/ha), dual-round harvest-aid application with a 7-day interval is needed because the lush leaves are blocking droplet penetration from the upper canopy layer. Both harvest aid dosages (exactly the recommended dosage or $80 \%$ of the recommended dosage) could make the defoliation rates and boll opening rates meet the mechanical harvest requirements. From the perspective of environmental protection and cost reduction, it is encouraged that the dosage applied should be the recommended dosage with a $20 \%$ reduction (defoliant: $540 \mathrm{~g} / \mathrm{L}$ thidiazuron and diuron $\mathrm{SC} 144 \mathrm{~mL} / \mathrm{hm}^{2}$; boll opener: $400 \mathrm{~g} / \mathrm{L}$ Ethephon AS $840 \mathrm{~mL} / \mathrm{hm}^{2}$; spray adjuvant: $280 \cdot \mathrm{g} / \mathrm{L}$ alkyl-ethyl-sulfonate adjuvant $720 \mathrm{~mL} / \mathrm{ha}$ ) to meet the requirements of the defoliation and boll opening rates for mechanical harvest (I-T2, III-T2 and IV-T2).

3) In all sites, the harvest aid dosage and the application frequency do not affect the fiber quality and lint cotton yield.

These results suggest that plant protection UAVs can be a substitute for ground-based harvest aid application sprayers. Based on the appropriate operational parameters, dosage and application frequency without loss of yield or affecting the fiber quality, it is feasible to use UAVs with low-volume spraying for harvest-aids application before the mechanical harvest.

\section{Funding}

This study is funded by National Key R\&D Program of China (grant number: 2017YFE0122400), National Key Research and Development Plan Program of China (grant number: 2016YFD0200700), China Agriculture Research System (grant number: CARS-15-22), the Leading Talents of Guangdong Province Program (grant number: 2016LJ06G689), Science and Technology Planning Project of Guangdong Province (grant number: 2017B010117010), The 111 Project (grant number: D18019) and National Natural Science Foundation of Guangdong Province, China (grant number: 2018B030306026).

\section{Declaration of Competing Interest}

The authors declare that they have no conflict of interest.

\section{[References]}

[1] Deguine J P, Ferron P, Russell D. Sustainable pest management for cotton production. A review. Agron Sustain Dev, 2008; 28: 113-137. https://doi.org/ 10.1051/agro:2007042.

[2] Feng L, Dai J L, Tian L W, Zhang H J, Li, W J, Dong H Z. Review of the technology for high-yielding and efficient cotton cultivation in the northwest inland cotton-growing region of china. Field Crops Res, 2017; 208:18-26. https://doi.org/10.1016/j.fcr.2017.03.008.

[3] Tian, X., Li, X., Lv, X., Li, B., Chen, G., 2016. Principles and Modern Technologies of Cotton Farming in Xinjiang. Science Press, Beijing, $182-381,1-44$.

[4] Duan J, Zhang X, Fan G, Liu G, Zhou G, Chu X, Chen X. Research on cotton defoliant spraying machinery and its application. China Cotton, 2013; 40:10-11. (in Chinese)

[5] Williamson J, Neilsen W. The influence of forest site on rate and extent of soil compaction and profile disturbance of skid trails during ground-based-based harvesting. Can. J. Forest Res, 2000; 30: 1196-1205. https://doi.org/10.1139/cjfr-30-8-1196.

[6] Xu R, Kuang R, Pay E, Dou H, De Snoo G R. Factors contributing to overuse of pesticides in western china. Environ Sci, 2008; 5: 235-249. https://doi.org/10.1080/15693430802346543.

[7] Wang X, Song Y. Comparative test of defoliant sprayed by aerial spraying and ground machine spraying. Xinjiang Agricultural Mechanization, 2003; 3: 20-22. (in Chinese) 
[8] Bae Y, Koo Y M. Flight attitudes and spray patterns of a roll-balanced agricultural unmanned helicopter. Appl Eng Agric, 2013; 29: 675-682. https://doi.org/10.13031/aea.29.10059.

[9] Chen T, Lu S. Autonomous navigation control system of agricultural mini-unmanned aerial vehicles based on DSP. Transactions of the CSAE, 2012; 28:164-169. https://doi.org/10.3969/j.issn.1002-6819.2012.21.023. (in Chinese)

[10] He X K, Bonds J, Herbst A. Langenakens, J. Recent development of unmanned aerial vehicle for plant protection in East Asia. Int J Agric \& Biol Eng, 2017; 10: 18-30. https://doi.org/10.3965/j.ijabe.20171003.3248.

[11] Krik I W, Hoffmann W C, Fritz B K. Aerial application methods for increasing spray deposition on wheat heads. Appl. Eng. Agric, 2006; 23: 357-364. https://doi.org/ 0.13031/2013.24052.

[12] Lan Y B, Chen S D, Fritz B K. Current status and future trends of precision agricultural aviation technologies. Int J Agric \& Biol Eng, 2017; 10: 1-17. https://doi.org/ 10.3965/j.ijabe.20171003.3088.

[13] Meng Y H, Lan Y B, Mei G Y, Guo Y W, Song J L, Wang Z G. Effect of aerial spray adjuvant applying on the efficiency of small unmanned aerial vehicle on wheat aphids control. Int J Agric \& Biol Eng, 2018, 11(5): 46-53. https://doi.org/10.25165/j.ijabe.20181105.4298

[14] Meng Y H, Song J L, Lan Y B, Mei G Y, Liang Z J, Han Y X. Harvest aids efficacy applied by unmanned aerial vehicles on cotton crop. Ind Crops Prod, 2019; 140. https://doi.org/10.1016/j.indcrop.2019.111645.

[15] Wang G, Lan Y, Yuan H, Qi H, Chen P, Fan Q, Han Y. Comparison of spray deposition, control efficacy on wheat aphids and working efficiency in the wheat field of the unmanned aerial vehicle with boom sprayer and two conventional knapsack sprayers. Appl Sci, 2019; 9. https://doi.org/10.3390/app9020218.

[16] Xue X, Lan Y. Agricultural aviation applications in USA. Transactions of the CSAE, 2013; 44: 194-199. https://doi.org/10.6041/j.issn.10001298.2013.05.034. (in Chinese)

[17] Zhou Z, Zang Y, Luo X, Lan Y, Xue X. Technology innovation development strategy on agricultural aviation industry for plant protection in China. Transactions of the CSAE, 2013; 29: 1-10. https://doi.org/ 10.3969/j.issn.1002-6819.2013.24.001. (in Chinese)

[18] Qin W, Qiu B, Xue X, Chen C, Xu Z, Zhou Q. Droplet deposition and control effect of insecticides sprayed with an unmanned aerial vehicle against plant hoppers. Crop Prot, 2016; 85: 79-88. https://doi.org/ 10.1016/j.cropro.2016.03.018. (in Chinese)

[19] Zhang P, Deng L, Lyu Q, He S, Yi S, Liu Y, Yu Y, Pan H. Effects of citrus tree-shape and spraying height of small unmanned aerial vehicle on droplet distribution. Int J Agric \& Biol Eng, 2016; 9: 45-52. https://doi.org/10.3965/j.ijabe.20160904.2178.

[20] Zhang P, Wang K, Lyu Q, He S, Yi S, Xie R, Zheng Y, Ma Y, Deng L. Droplet distribution and control against citrus leafminer with UAV spraying. Int J Robot Autom, 2017; 32: 299-307. https://doi.org/10.2316/Journal.
206.2017.3.206-4980.

[21] Wang Z, Feng H Z, Wang L, Ma X Y, Gou C Q, Xiao H B, Huang Q. Effects comparison of different defoliants applied by MG-1S unmanned Aerial Vehicle in cotton field. China cotton, 2018; 45: 27--28, 46. (in Chinese)

[22] Ma Y, Ren X, Meng Y, Song J, Ma D, Liu Z, Fu W, Jiang W, Hu H, Wang D, Wang Z, Lan Y. Review on Result of Spraying Defoliant by Unmanned Aerial Vehicles in Cotton Field of Xinjiang. China Cotton, 2016; 43: 16-20. (in Chinese)

[23] Xin F, Zhao J, Zhou Y, Wang G, Han X, Fu W, Deng J, Lan Y. Effects of Dosage and Spraying Volume on Cotton Defoliants Efficacy: A Case Study Based on Application of Unmanned Aerial Vehicles. Agronomy, 2018; 8: 85. https://doi.org/10.3390/agronomy8060085.

[24] Monaco T J, Weller S C, Ashton F M. Weed Science: Principles and Practices. 4th ed. 2002; New York, NY. John Wiley \& Sons, Inc.

[25] Zhu, H., Salyani, M., Fox, R.D. A portable scanning system for evaluation of spray deposit distribution. Comput Electron Agr, 2011; 76, 38-43. https://doi.org/10.3969/10.1016/j.compag.2011.01.003.

[26] Cunha M, Carvalho C, Marcal A R S. Assessing the ability of image processing software to analyse spray quality on water-sensitive papers used as artificial targets. Biosyst Eng, 2012; 111: 11-23. https://doi.org/ 10.1016/j.biosystemseng.2011.10.002.

[27] GFET[Guidelines for the field efficacy trials (II)--Part 134: Plant growth regulator trials on cotton]. GB/T 17980.134-2004, Beijing: Standards Press of China. (in Chinese)

[28] Siebert J D. Cotton (Gossypium hirsutum L.) response to plant density, insect pest management, and harvest-aid application strategies. LSU Doctoral Dissertations, 2005. https://digitalcommons.lsu.edu/ gradschool dissertations $/ 2505$.

[29] Fan Q, Chen Y, Chen G. Matching technology of defoliation and ripening for machine harvesting cotton. Xinjiang Farmland Res Sci \& Tech, 2009; 32: 6-7. (in Chinese)

[30] Liu X, Zhu X, You J, Zhao Z. Optimization of defoliant spraying method for machine harvesting cotton. Xinjiang Farmland Res Sci Tech, 2016; 39: 55-58. (in Chinese)

[31] Stewart A, Edmisten K, Wells R. Boll openers in cotton: Effectiveness and environmental influences. Field Crops Res, 2000; 67: 83-90. https://doi.org/10.1016/s0378-4290(00)00093-9.

[32] Sun Y, Li W, Hu X, Feng Y. Effect of defoliant on defoliation and boll opening in Upland cotton cultivars. China Cotton, 2011; 38: 28-29. (in Chinese)

[33] Robertson W C, Rodery S, Ballantyne P. Evaluation of harvest aids on dryland and irrigated cotton. Special Report Arkansas Agricultural Experiment Station, 1998; 188: 161-164.

[34] Holman E M, Crawford S H, Coco A B. Harvest-aid chemical in cotton: their influence on yield and fiber quality. Louisiana Agriculture, 1998; 41 , 26-27. 